\title{
The EFFect of Screen Size on Students' Cognitive LoAd In Mobile LEARNING
}

\author{
Talal Alasmari \\ University of Jeddah, Jeddah, Saudi Arabia \\ E-mail: talasmari@uj.edu.sa
}

\begin{abstract}
Mobile learning is becoming a crucial tool in this era of face-to-face shutdown of education, and however the whole process currently faces a significant deficiency due to the kind of cognitive load that does exist and its relation with mobile device screen display size. It is well-established that certain screen sizes are more effective than others. This study aims to investigate the effect of screen size on students' cognitive load in mobile learning. Specifically, it investigates whether screen size has a role in cognitive role and draws a comparison to reflect on the most effective size to be used in the context of mobile learning. Other factors that might interfere in the process were also investigated which include course content, gender, age, and students' GPA to see whether they play any additional role in burdening the cognitive load when using different screen sizes. To test the effect of screen size on cognitive load, an online survey was distributed to 1,570 students of the University of Jeddah who are studying at the foundation year for the academic year of 2018-2018, particularly for eight online courses. The sample was chosen randomly, where all members of the population, 6,500 students, had equal opportunities to participate in the study. Participants were invited via e-mail by sending an invitation to participate along with the questionnaire link on the "Qualrrics" platform. This research data analysis technique used ANOVA and curve estimation. The research findings revealed that small screen display size produces the lowest cognitive load as compared with larger display screens. This study also supports the use mobile learning process and gives recommendations to the instructional designers in order to make learning experiences more effective. The results of this study suggest a proper use of screen size can improve learning from smartphones, making them equal to learning from laptops and reducing the overloaded cognitive load that may affect students' understanding and hinder retention. Hence, implications were discussed, and further research recommendations were then provided.
\end{abstract}

Keywords: Mobile Leaning; Screen Size; Mobile Screen; Handheld Device; Cognitive Load

\section{INTRODUCTION}

Mobile Learning Technology (MLT) is an effective tool in learning systems, and this brings learning with mobile devises under focus. These devices offer applications and access to material for all kinds of learners of all ages. Therefore, educators and instructional designers are working hard to find the best medium that leads to the best learning experiences.

Mobile learning technology (MLT) has become the fastestgrowing source of information and knowledge. M-learning is an innovative learning across multiple contexts, through social and content platform, using by virtual media sources (Crompton, 2013). The role of M-learning in today's flow of ideas and information is the highest in mankind's history. Cognitive load is the load created by the information with the brain (Sweller, 1994). Cognitive load associated with the brain cells play a vital role in processing the information in the mind. However, there are many factors linked due to which cognitive load increases or decreases in the brain (Sweller, 1988).

There are majorly three types of cognitive loads i.e. intrinsic, extraneous, and germane. Each type of cognitive load has revealed cognitive load has a strong link with screen size. Moreover, the relation between students' mobile learning, their grades, and the screen size they use, shows a clear indication of this (Sweller, 1988). As mobile learning moves from one context to another, more psychological challenges get involved. These challenges include but are not limited to the interruption, distraction, and concentration reduction. Such challenges may lead to less engagement with learning and consequently, less achievement in learning tasks (Terras \& Ramsay, 2012). It is noticed such a risk on learners' cognitions, where human limited working memory is easily overloaded under such conditions, which is defined as cognitive load (Sweller, 1994). The sentiments of dealing with the cognitive load ultimately mean the effectiveness of information. 
M-learning technology depends critically upon screen size of the electronic device. The importance of screen size gets critically important when it comes to M-learning and effective learning (Sweller, 1988). Screen size also affects the information-learning by constricting the display of information in ways that turn the user experiences and structure their expectations about the utility and functionality of mobile devices for information-seeking (Chae \& Kim, 2004; Kim et al., 2011; Kim \& Sundar, 2014). Screen size is positively corresponding with ease of reading, clarity and presentation of information, and negatively associates with reading and learning time (Molyneux, 2015). Chae and Kim (2004) has reported that mobile devices have many usability limitations, such as small screens that reduce the richness and effectiveness of information presented, limited display capabilities that require users to remember the content of a web page and then later find more information on it by clicking or scrolling (Ghose et al., 2012). Nipan et al. (2008) reported that users tend to learn less information from video content especially on a small screen, and reports that it is more difficult to access higher volumes of information while using mobile screens. The mobile phone features create negatively affect users' satisfaction only when the task complexity increases (Chae \& Kim, 2004; Napoli \& Obar, 2014).

Mobile learning itself impacts the efficiency, effectiveness of information, and knowledge. The mobile screen size also has critical importance to the success of effective learning (Mavromoustakos, 2006). This crucial research interrogates the effect of smartphone screen size and its association on cognitive load. What is the exact level of cognitive load for a better understanding of information, this paper interrogates the matter? This research ultimately improves the understanding of effective M-Learning and importance of cognitive load by contributing literature to the existing and available findings. The new findings aim to provide implications that could furthermore be proceeded commercially by instructional designers in mobile technology designing productive and efficient M-learning content.

This paper investigates the effect of screen size on cognitive load in mobile learning. The aim has change to investigate the relationship between screen size and cognitive load in mobile learning. Therefore, the research key questions are:

1. What is the effect of device screen size on cognitive load (intrinsic, extraneous, total cognitive load)?

2. Do course content, gender, age, and students' GPA affect the level of cognitive load?

3. Does device screen size affect intrinsic and extraneous cognitive load with regards to course, gender?

\section{LITERATURE REVIEW}

The mobile device has become the most used technology worldwide. Because of its attractive features such as mobility, productivity, and convenience. However, if we compare it with a desktop, we may find that mobile devices face many challenges and obstacles. For instance, storage, bandwidth, processor speed, and small screen size, which makes it a challenge for mobile device developers (Nipan, 2008).

\section{A. Cognitive Load Theory}

Humans have a limited amount of working memory resources to consume, known as cognitive load. It is further subdivided into three types: intrinsic, extraneous, and germane. The intrinsic cognitive load is related to the one that is specific to the instructional topic's inherent level of difficulty. Extraneous cognitive load is cognitive load generated through the weak and disorganized presentation of any information. However, germane cognitive load is an automated load created by processing and construction of schemas. Cognitive load theory is an important research framework in the field of education and learning research. Cognitive load theory has major implications in different fields of education. Most importantly, it deals with the brain and ultimately, all the scope of studies (Sweller, 1994).

\section{B. Measurement of Cognitive Load}

The literature of cognitive load indicates that there are different measurements for cognitive load. One classification is based on the directivity of the causal relationship between the observed phenomenon and the attribution; that resulted in two classifications: direct and indirect measurements. Other classifications are based on the objectivity of the measurements, where the method of the measurement is subjective when using self-reporting, and objective when using physiological techniques, such as heartbeats. Other cognitive load measurements are task and performance-based, where cognitive load is measured based on the task difficulty or learners' performances (Brunken, Plass, \& Leutner, 2003; Cheng et al., 2014).

During learning, the information first processed in working memory and later stored in long-term memory. Thus, measuring the cognitive load is challenging and complicated (Klepsch et al., 2017). There are various methodologies of measuring the cognitive load that can be adopted. Few of them are top of the list, self-report measures, dual-task measures, and physiological parameters.

In a self-report, a rating scale is used to measure task difficulty. A 9-point Likert scale is used to record responses, ranging from an investment of very lowest mental effort to the highest mental tension (Paas et al., 2003). So, it can easily understand through the learner's response. However, in a dual-task measure, a learner is required to perform two tasks at one time. The observer's focus throughout the process is estimating the load of the first work; either it gives space to the second task in mind or not. It can be carried out in two possible ways, measure perfection and response time or measure concurrent second task that the learner performs along (Brünken et al., 2004; Park et al., 2011). In this way, the researcher can judge cognitive load more accurately and precisely because the subject is just examined, not asked anything, and later the results are extracted.

The third method of measurement is physiological parameters, where different types of physiological indicators have been measured i.e., heart rate, pupil dilation (Paas et al., 1994; Gerven et al., 2004). In this way, cognitive load is estimated by measuring the stress it puts on the human body. Previous studies discussed different scope of research on 
cognitive load and its practical implications. This research specifically covers the relationship between cognitive load and mobile technology will have a significant impact on the productivity of education sector.

\section{Cognitive Load and Mobile Learning}

Cognitive load is a kind of load created by the flow of information on the processing and storage of brain. This is created due to several reasons including overloading of information at a same time or poor presentation and others (Sweller, 1988).

In the literature, many independent variables interact with cognitive load directly either presentational or instructional variables. For presentational variables, there are several reasons for the frequent study of presentation variables in $\mathrm{m}$ learning cognitive load. First, extraneous cognitive load is the only type of cognitive load that can be manipulated by researchers through manipulating the way of presenting information, while the other two types of cognitive load, intrinsic and germane, are fixed and cannot be manipulated. Thus, researchers focus their attention on presentation variables to reduce the extraneous cognitive load and improve learning accordingly. Second, the physical limitations of mobile technology screens challenge researchers to create different presentation methods that facilitate achieving desired learning outcomes. Third, the mobility advantage of hand-held devices encourages researchers to design different mobile learning interfaces that fit different learning contexts (Wenhao, David, \& Jeanette, 2014). Hence, instructional design manifests as an appropriate solution to reduce cognitive load through the introduction of creative presentations of information on mobile technology screens.

Instructional strategy variables such as inquiry-based learning, learning with formative assessment, mobile learning model in an authentic learning environment, and problembased mobile learning are other category that is manifested in the literature. Studies such as Hwang et al. (2010), Hwang et al. (2017), and Chu (2014) tend to employ instructional strategies that hypothesized to fit a specific learning context. Further, authentic learning theory was employed with some presentation variables (Chang et al., 2011; Liu et al., 2013; Shadiev et al., 2015). Other variables, such as source of cognitive load and distraction effect on cognitive load, have been recorded in Deegan (2015) study.

Cognitive load and mobile learning are inter-linked with each other. Within the discussed literature there is no proper work regarding the domain of M-learning and cognitive load together. In cognitive load, only type-b i.e. extraneous can be influenced. However, cognitive load is influenced by different factors and variables which are discussed furthermore.

\section{Screen Size and Cognitive Load}

Screen size is linked with the cognitive load in such a way that it becomes the most important factor that plays the vital role in the quality of the experience (QoE) of mobile learning (Triyason \& Krathu, 2017). Therefore, it is essential to address the effects of screen size to make mobile learning more productive and less distracting for students. Moreover, many previous studies have shown that screen size is critical to the success of effective learning (Wang \& Higgins, 2005; Papanikolaou \& Mavromoustakos, 2006). Naylor \& Sanchez (2018) investigated if the difficulty level linked with reading on small screens translate into various reactions toward the information presented on devices.

In the wider fields, the mobile device's screen size has different effects on several human factors, such as psychology. For instance, Naylor \& Sanchez (2018) addressed the extent to which screen size affects remembering the material being viewed across two different display screens (4, 5.5 inches). The results indicated that the participants recalled the information similarly across the two screens. However, the larger display did produce more attitude toward the material as well as increasing the readability (Ghamdi et al., 2015; Wang et al., 2013). This is consistent with the results of Kim \& Sundar (2014), who also asserted that screen size influences the user's attitude, leading to higher smartphone adoption indirectly.

In the same context, Raptis et al. (2013) investigated the effect of three different mobile screen sizes (3.5, 4.3, 5.3 inches) on the users' perceived usability, effectiveness, and efficiency during information-seeking tasks. They found out that the largest screen increased the user's efficiency (task completion time) (Hu et al., 2016). However, there was no significant effect on perceived usability and effectiveness.

Screen size has drew the attention of emotional and immersion studies where Hou et al. (2012) found that the largest screen size had a positive effect on the player's feeling of involvement and participation, self-presence, their impression on the game characters and the players' mood as well as on multimodal synergy (Sluis et al., 2018). In contrast, Furió et al. (2013) result indicated that screen size did not have an influence on the engagement, satisfaction, ease of use, and experience of the players.

Additionally, reduced screen sizes also affected the user's behavioral activities, perceptions, and cognitive load. Chae \& Kim (2004) explained that a small screen size increased both BPN (between page navigation) paging backward, forwards, and WPN (scrolling activities within a single page) which in turn, increased the user frustration and fatigue, which places heavy cognitive demands on the user's memory (Byrd \& Caldwell, 2011). On the contrary, Karam (2015) pointed out that screen size does not affect cognitive load and learning outcomes. However, they agree that it does matter with the user perception context. In relation to information processing, a large screen display promotes heuristic information processing, which leads to greater effective and behavioral trust that affects purchase-related decisions (Kim \& Sundar, 2016).

The relationship between screen size and attention in multitasking activities has been examined by Castro (2017). The study suggested that individuals using a small screen size have a higher performance concerning the background change and detection task than those using the largest screen size, proving that small screens may be less attention-demanding when the attention is divided. 
A few studies were conducted in the literature to investigate the effect of screen size on student academic achievements. Kim \& Kim (2012) suggested that smaller screen devices have been less effective for simple tasks like vocabulary learning, determined by conducting a post-test and retention test. Similarly, Park et al. (2018) conducted two experiments on three mobile screen-sizes $(3.5,7,10.1$ inches). The findings revealed that the students with the largest screen scored higher on the test and expressed greater satisfaction with the course. Thus, they emphasized that larger screen size is more effective when used to provide mobile learning than smaller screen size. This study is concerned with the role of mobile screen size and its effects on the students' academic achievement during m-learning. Students these days tend to use mobile devices extensively, as shown in many studies (Alalwan et al., 2018; Parsazadeh et al., 2018; So, 2016). Hence, it is essential to address this gap by undertaking this research. It will further be beneficial for researchers on designing effective mobile technology concerning human productivity.

\section{METHODOLOGY}

The study is descriptive, and it analyzed the effect of different screen sizes of mobile devices on students' cognitive loads. Cognitive load in this study was measured using a selfreported scale that was developed by Badawi (2014). To measure the two main dependent variables which are: intrinsic and extraneous cognitive load, a scale was made of thirty items: fifteen items measure intrinsic cognitive load, and fifteen items measure extraneous cognitive load. A quantitative method provides the means to capture students' cognitive loads during their learning experiences with different screen sizes of mobile devices. The psychometric evaluation of the scale calculated through Cronbach's alpha and bivariate correlations tests that is presented in the psychometric analysis of cognitive load scale section.

The study population included 6,500 male and female students who are studying at the foundation year at University of Jeddah for the academic year 2018-2018. The sample size was 1,570 students who responded to the research questionnaire. $589(37.5 \%)$ of the participants were male. 981 $(62.5 \%)$ of the participants were female. The sample was chosen randomly, in which all members of the population had equal opportunities to participate in the study. Participants were recruited via e-mail by sending an invitation to participate along with the questionnaire link on the Qualrics platform. On the other hand, the study investigate four types of mobile devices' screen sizes as independent variables as follows: Small Screen Smartphone (4 Inches), Large Screen Smartphone (5.5 Inches), Small Screen iPad or Tablet (7.9 Inches), and Large Screen iPad or Tablet (9.7 Inches).

This study used a random sampling technique where all students studying all eight online courses were invited through university official emailing system. Cognitive load questionnaire was sent through an online surveying system that keeps reminding participants of their participation in the study to increase the recruitment in this study. This study employed a descriptive research design through using a cross- sectional approach to collect data. The questionnaire was sent out near the end of the semester to ensure that all participants have a full insight of their course and familiarized themselves with mobile devices that are using.

\section{A. Psychometric evaluation of the research instrument}

\section{1) Reliability Diagnostics}

According to Table I, Cronbach's alpha was used to assess whether the 15 items used to measure 'intrinsic cognitive load' (i.e. Q 01 to Q 15) are reliable enough or not. The Cronbach's alpha was found to be 0.884 , which is a high number and thus, the 15 items used to measure 'intrinsic cognitive load' are reliable enough to measure it.

In addition, Cronbach's alpha was again used to assess whether the 15 items used to measure 'extraneous cognitive load' (i.e., Q_16 to Q_30) are reliable enough or not. The Cronbach's alpha was found to be 0.913 , which is a high number and thus, the 15 items used to measure 'extraneous cognitive load' are indeed reliable enough to measure it.

Moreover, Cronbach's alpha was again used to assess whether the 30 items used to measure total cognitive load (i.e., Q_01 to Q_30) are reliable enough or not. The Cronbach's alpha was found to be 0.946 , which is a high number and thus, the 30 items used to measure 'total cognitive load' are indeed reliable enough to measure it.

TABLE I

VALUES OF CRONBACH'S ALPHA RELIABILITY COEFFICIENT FOR THE QUESTIONNAIRE SCALES

\begin{tabular}{lll}
\hline Scale & Cronbach's Alpha & N of Items \\
\hline $\begin{array}{l}\text { Intrinsic Cognitive } \\
\text { Load (Items 1-15) }\end{array}$ & 0.884 & 15 \\
$\begin{array}{l}\text { Extraneous Cognitive } \\
\text { Load (Items 16-30) }\end{array}$ & 0.913 & 15 \\
\hline $\begin{array}{l}\text { Total Cognitive Load } \\
\text { (Items 1-30) }\end{array}$ & $\mathbf{0 . 9 4 6}$ & $\mathbf{3 0}$ \\
\hline
\end{tabular}

\section{2) Validity Diagnostics}

Validity of each item in the questionnaire has been tested using bivariate correlation matrix (BCM) method. Table 2 indicates that each of the item's correlation with total cognitive load is statistically significant (i.e. market with *). This implies that all 30 items (i.e. Q_1 to Q_30) are valid.

\section{B. Statistical Analysis}

To answer the questions of the current study, ANOVA and curve estimation were the two amin statistical techniques that were used. Since the primary investigation was to determine if there is any statistical significance difference between groups' means (i.e. device screen sizes), ANOVA was used to test the differences between these means. Curve estimation technique is used to determine which of the models (i.e. linear, quadratic, exponential, inverse, cubic, compound or power etc.) best describes the relationship between two variables. Bivariate correlation matrix of the questionnaire items can be seen in Table II. 
TABLE II

BIVARIATE CORRELATION MATRIX OF THE QUESTIONNAIRE ITEMS

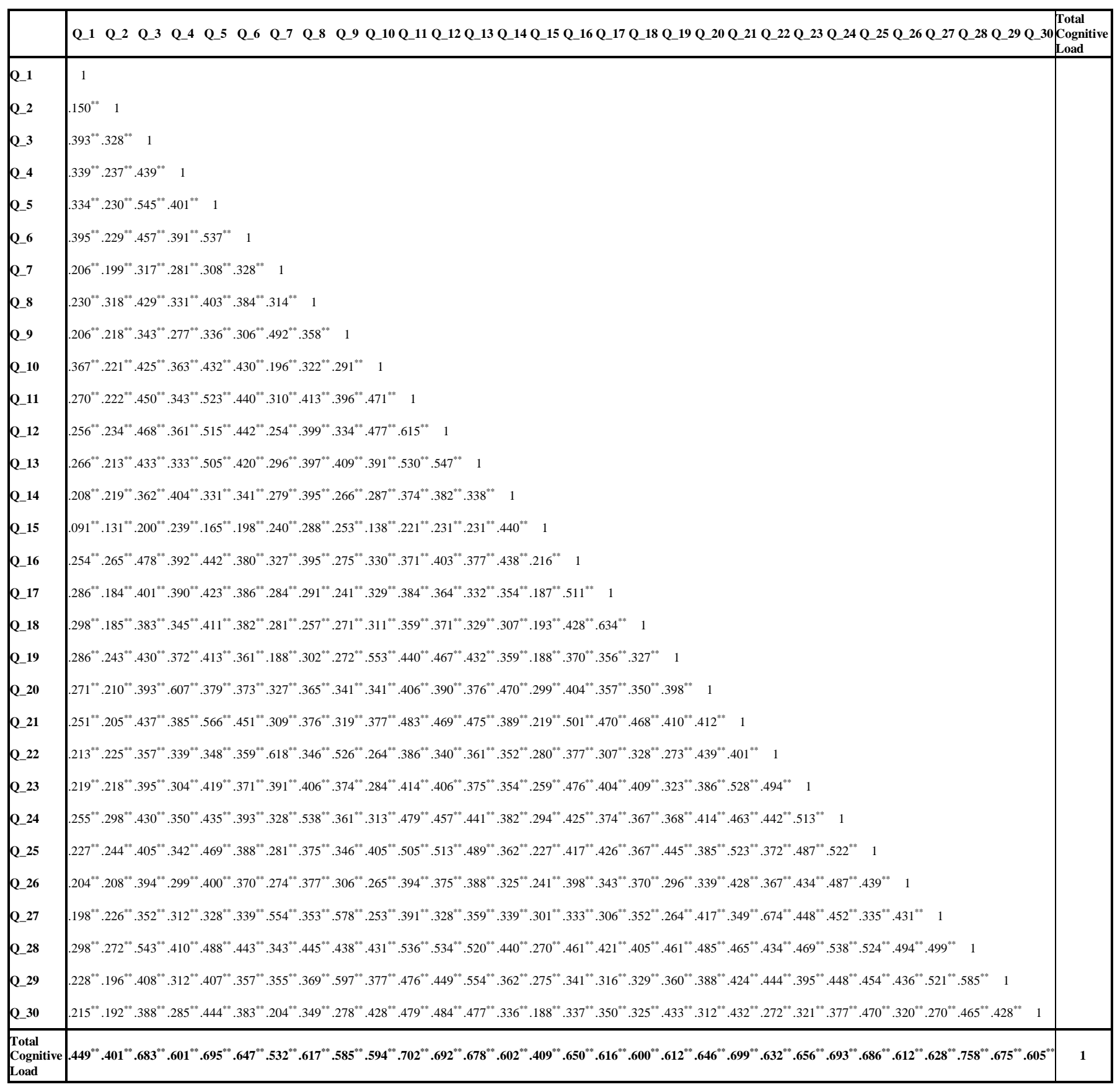

**. Correlation is significant at the 0.01 level (2-tailed). $\mathrm{N}=1,570$

\section{IV.RESULTS AND DISCUSSION}

\section{A. Results}

The results of this study have shown that screen size matters most for cognitive load, and that the small screen smartphone is the best since it leads to the lowest intrinsic cognitive load; large screen $\mathrm{iPad} /$ tablet is the second best option since it leads to the second lowest intrinsic cognitive load, large screen smartphone is the third best since it leads to the second highest intrinsic cognitive load, and small screen
$\mathrm{iPad} / \mathrm{tablet}$ is the worst since it leads to the highest intrinsic cognitive load. The questions of this study can be answered with digits using ANOVA and curve estimation. Curve estimation or regression could be noticeably used in this case because 'device screen size' is an ordinal variable instead of a categorical variable i.e. value of the variable rises from 1 to 4 as screen size increases from 4-inches to 9.7-inches. Thus, regression coefficient would have meaningful interpretation.

1) The Effect of Device Screen Size on Cognitive Load (Intrinsic, Extraneous, Overall) 
a) Effect of Device Screen Size on Intrinsic Cognitive Load

The effect of different specified screen size on intrinsic cognitive load is proved crucial and important. The statistical representation of the findings can be seen in Table III and Table IV.

TABLE III

THE MEAN AND SD OF SCREEN SIZE AND INTRINSIC COGNITIVE LOAD

\begin{tabular}{|c|c|c|c|c|c|c|c|c|}
\hline & \multirow[t]{2}{*}{$\mathbf{N}$} & \multirow[t]{2}{*}{ Mean } & \multirow[t]{2}{*}{$\begin{array}{c}\text { Std. } \\
\text { Deviation }\end{array}$} & \multirow[t]{2}{*}{$\begin{array}{c}\text { Std. } \\
\text { Error }\end{array}$} & \multicolumn{2}{|c|}{$\begin{array}{l}\text { 95\% Confidence } \\
\text { Interval for Mean }\end{array}$} & \multirow[t]{2}{*}{ Minimum } & \multirow[t]{2}{*}{ Maximum } \\
\hline & & & & & $\begin{array}{l}\text { Lower } \\
\text { Bound }\end{array}$ & $\begin{array}{l}\text { Upper } \\
\text { Bound }\end{array}$ & & \\
\hline $\begin{array}{l}\text { Small screen smartphone } \\
\text { (4 inches) }\end{array}$ & 543 & 1.8415 & 0.49754 & 0.02135 & 1.7996 & 1.8834 & 1 & 3 \\
\hline $\begin{array}{l}\text { Large screen smartphone } \\
\text { (5.5 inches) }\end{array}$ & 823 & 1.9043 & 0.49496 & 0.01725 & 1.8704 & 1.9381 & 1 & 3 \\
\hline $\begin{array}{l}\text { Small screen iPad/Tablet } \\
\text { (7.9 inches) }\end{array}$ & 39 & 1.9333 & 0.49865 & 0.07985 & 1.7717 & 2.095 & 1 & 2.93 \\
\hline $\begin{array}{l}\text { Large screen iPad/Tablet } \\
\text { (9.7 inches) }\end{array}$ & 165 & 1.8719 & 0.5037 & 0.03921 & 1.7945 & 1.9493 & 1 & 3 \\
\hline Total & 1,570 & 1.8799 & 0.49729 & 0.01255 & 1.8553 & 1.9045 & 1 & 3 \\
\hline
\end{tabular}

TABLE IV

ANOVA FOR INTRINSIC COGNITIVE LOAD

\begin{tabular}{lccccc}
\hline & Sum of Squares & df & Mean Square & F & Sig. \\
\hline Between Groups & 1.411 & 3 & .470 & 1.905 & 0.127 \\
Within Groups & 386.604 & 1566 & .247 & & \\
\hline Total & $\mathbf{3 8 8 . 0 1 5}$ & $\mathbf{1 5 6 9}$ & & & \\
\hline
\end{tabular}

The ANOVA reveals the following insights related to the research problem. The descriptive statistics and the means plot show that the highest intrinsic cognitive load on average (1.933) is faced by those students who used small screen iPad/Tablet (7.9 inches) while the lowest intrinsic cognitive load on average (1.8415) is faced by those students that used small screen smartphone (4 inches). But the ANOVA p-value is 0.127 i.e. higher than 0.05 . Thus, the differences in intrinsic cognitive load faced by students in terms of screen size used were statistically insignificant at the $5 \%$ significance level.

Curve estimation technique is used to determine which models (i.e., linear, quadratic, exponential, inverse, cubic, compound or power, etc.) best describe the relationship between two variables.
The R-squared is highest (i.e. 0.004) in case of cubic model. This implies that the relationship between device screen size and intrinsic cognitive load is best described as 'cubic'. The regression equation can be seen in equation (1).

Intrinsic cognitive load $=1.755+0.090 *$ Device screen size + $0.000 *$ Device screen size $2-0.004 *$ Device screen size 3

b) Effect of Device Screen Size on Extraneous Cognitive Load

The effect of different specified screen size on extraneous cognitive load is proved crucial and important. The statistical representation of the findings can be seen in Table $\mathrm{V}$ and Table VI.

TABLE V

THE MEAN AND SD OF SCREEN SIZE AND EXTRANEOUS COGNITIVE LOAD

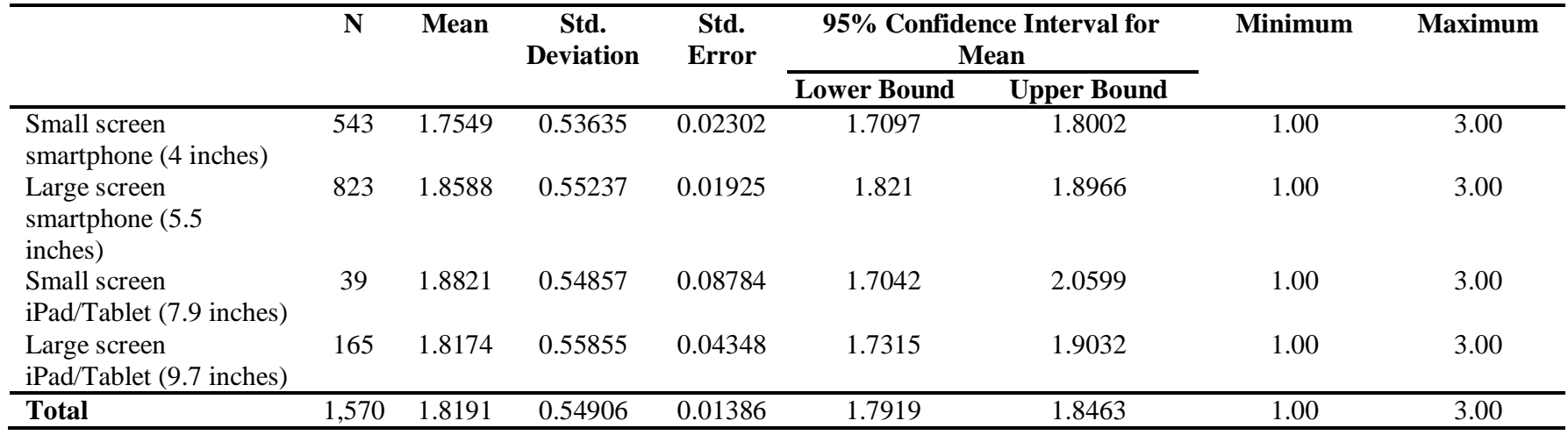


TABLE VI

ANOVA FOR EXTRANEOUS COGNITIVE LOAD

\begin{tabular}{lccccc}
\hline & Sum of Squares & df & Mean Square & F & Sig. \\
\hline Between Groups & 3.688 & 3 & 1.229 & 4.102 \\
Within Groups & 469.312 & 1566 & .300 & 0.007 \\
\hline Total & $\mathbf{4 7 3 . 0 0 0}$ & $\mathbf{1 5 6 9}$ & & \\
\hline
\end{tabular}

The ANOVA reveals the following insights related to the research problem. The descriptive statistics and the means plot show that the highest extraneous cognitive load on average (1.8821) is faced by those students that used small screen iPad/Tablet (7.9 inches) while the lowest extraneous cognitive load on average (1.7549) is faced by those students that used small screen smartphone (4 inches). Consider that the ANOVA p-value is 0.007 i.e. lower than 0.05. Thus, the differences in extraneous cognitive load faced by students in terms of screen size used were statistically significant at the $5 \%$ significance level.

The R-squared is highest (i.e., 0.008) in the case of cubic model. It implies that the relationship between device screen size and extraneous cognitive load is best described as 'cubic'. The regression equation can be seen in equation (2).

Extraneous cognitive load $=1.568+0.229 *$ Device screen size $-0.042 *$ Device screen size $2+0.000 *$ Device screen size 3
Thus, small screen smartphone is the best since it leads to the lowest extraneous cognitive load; large screen iPad/tablet is the second best since it leads to the second lowest extraneous cognitive load, large screen smartphone is the third best since it leads to the second highest extraneous cognitive load, and small screen $\mathrm{iPad} /$ tablet is the worst since it leads to the highest extraneous cognitive load.

\section{c) Effect of Screen size on Total Cognitive Load}

The effect of device screen size on total cognitive load is directly related. It shows that a small smartphone screen size is the best since it leads to the lowest total cognitive load in comparison. Here the question rises why not large-screen smartphones been prioritized, the answer to this query has justified briefly. This research could be explained using ANOVA and curve estimation. Curve estimation or regression could be noticeably used in this case due to the reason provided before. The ANOVA can be seen in Table VII and Table VIII.

TABLE VII

THE MEAN AND SD OF SCREEN SIZE AND INTRINSIC COGNITIVE LOAD

\begin{tabular}{|c|c|c|c|c|c|c|c|c|}
\hline & \multirow[t]{2}{*}{$\mathbf{N}$} & \multirow[t]{2}{*}{ Mean } & \multirow[t]{2}{*}{$\begin{array}{c}\text { Std. } \\
\text { Deviation }\end{array}$} & \multirow[t]{2}{*}{$\begin{array}{l}\text { Std. } \\
\text { Error }\end{array}$} & \multicolumn{2}{|c|}{$\begin{array}{l}\text { 95\% Confidence } \\
\text { Interval for Mean }\end{array}$} & \multirow[t]{2}{*}{ Minimum } & \multirow[t]{2}{*}{ Maximum } \\
\hline & & & & & $\begin{array}{l}\text { Lower } \\
\text { Bound }\end{array}$ & $\begin{array}{l}\text { Upper } \\
\text { Bound }\end{array}$ & & \\
\hline $\begin{array}{l}\text { Small screen smartphone } \\
\text { (4 inches) }\end{array}$ & 543 & 3.5964 & 1.0015 & 0.04298 & 3.512 & 3.6809 & 2.00 & 6.00 \\
\hline $\begin{array}{l}\text { Large screen smartphone } \\
\text { (5.5 inches) }\end{array}$ & 823 & 3.7631 & 1.00766 & 0.03512 & 3.6941 & 3.832 & 2.00 & 6.00 \\
\hline $\begin{array}{l}\text { Small screen iPacI/Tablet } \\
\text { (7.9 inches) }\end{array}$ & 39 & 3.8154 & 1.02077 & 0.16345 & 3.4845 & 4.1463 & 2.00 & 5.93 \\
\hline $\begin{array}{l}\text { Large screen iPad/Tablet } \\
\text { (9.7 inches) }\end{array}$ & 165 & 3.6893 & 1.03128 & 0.08029 & 3.5308 & 3.8478 & 2.00 & 6.00 \\
\hline Total & 1,570 & 3.699 & 1.01044 & 0.0255 & 3.649 & 3.749 & 2.00 & 6.00 \\
\hline
\end{tabular}

TABLE VIII

ANOVA FOR TOTAL COGNITIVE LOAD

\begin{tabular}{lccccc}
\hline & Sum of Squares & df & Mean Square & F & Sig. \\
\hline Between Groups & 9.633 & 3 & 3.211 & 3.158 & .024 \\
Within Groups & 1592.296 & 1566 & 1.017 & & \\
\hline Total & $\mathbf{1 6 0 1 . 9 2 9}$ & $\mathbf{1 5 6 9}$ & & & \\
\hline
\end{tabular}

The ANOVA reveals the following insights related to the research problem. The descriptive statistics and the means plot show that the highest total cognitive load on average (3.81) is faced by those students that used small screen iPad/Tablet (7.9 inches) while the lowest total cognitive load on average (3.51) is faced by those students that used small screen smartphone (4 inches). Consider that the ANOVA p-value is 0.024 i.e. lower than 0.05. Thus, the differences in total cognitive load faced by students in terms of screen size used were statistically significant at the 5\% significance level.

The R-squared is highest (i.e., 0.006) in the case of cubic model. It implies that the relationship between device screen size and total cognitive load is best described as 'cubic'. The regression equation can be seen in equation (3). 
Total cognitive load $=3.371+0.235 *$ Device screen size + $0.000 *$ Device screen size $2-0.010 *$ Device screen size 3

Thus, a small screen smartphone is the best since it leads to the lowest total cognitive load; a large screen $\mathrm{iPad} / \mathrm{tablet}$ is the second best since it leads to the second-lowest total cognitive load, the large-screen smartphone is the third-best since it leads to the second-highest total cognitive load. A small screen $\mathrm{iPad} / \mathrm{tablet}$ is the worst since it leads to the highest total cognitive load.

2) The Effect of Course, Gender, Age, and Students' GPA on the Level of Cognitive Load a) The Effect of Courses on Cognitive Load

This research problem could be answered using ANOVA only. Curve estimation or regression could not have been used because 'courses' is a categorical variable, and not an ordinal one. Thus, the regression coefficient would have no meaningful interpretation. 'Courses' is a categorical variable and not an ordinal variable like 'device screen size' because a rise in the value of variable 'courses' from let's say 1 to 2 does not indicate a rise in something i.e., instead, it shows a change in course from ETEC 100 to EPHS 100. On the other hand, 'device screen size' is an ordinal variable because a rise in the coded value of variable 'device screen size' from let's say 1 to 2 indicates a rise in screen size from 4 inches to 5.5 inches. The ANOVA can be seen in Table IX and Table X.

TABLE IX

THE MEAN AND SD OF COURSES AND COGNITIVE LOAD

\begin{tabular}{|c|c|c|c|c|c|c|c|c|c|}
\hline & \multirow[t]{2}{*}{ Course } & \multirow[t]{2}{*}{$\mathbf{N}$} & \multirow[t]{2}{*}{ Mean } & \multirow[t]{2}{*}{$\begin{array}{c}\text { Std. } \\
\text { Deviation }\end{array}$} & \multirow[t]{2}{*}{$\begin{array}{c}\text { Std. } \\
\text { Error }\end{array}$} & \multicolumn{2}{|c|}{$\begin{array}{c}95 \% \text { Confidence } \\
\text { Interval for } \\
\text { Mean } \\
\end{array}$} & \multirow[t]{2}{*}{ Minimum } & \multirow[t]{2}{*}{ Maximum } \\
\hline & & & & & & $\begin{array}{l}\text { Lower } \\
\text { Bound }\end{array}$ & $\begin{array}{l}\text { Upper } \\
\text { Bound }\end{array}$ & & \\
\hline \multirow{10}{*}{$\begin{array}{l}\text { Intrinsic } \\
\text { Cognitive } \\
\text { Load }\end{array}$} & $\begin{array}{l}\text { University Study Skills } \\
\text { (ETEC100) }\end{array}$ & 261 & 2.0843 & 0.44096 & 0.02729 & 2.0305 & 2.138 & 1.00 & 3.00 \\
\hline & $\begin{array}{l}\text { Physical Fitness Skills } \\
\text { (EPHS100) }\end{array}$ & 19 & 1.9754 & 0.59137 & 0.13567 & 1.6904 & 2.2605 & 1.07 & 2.93 \\
\hline & $\begin{array}{l}\text { Entrepreneurship Skills } \\
\text { (BUS100) }\end{array}$ & 19 & 1.9965 & 0.50649 & 0.1162 & 1.7524 & 2.2406 & 1.07 & 2.73 \\
\hline & Islamic Culture I (ISLM101) & 71 & 1.8113 & 0.43991 & 0.05221 & 1.7071 & 1.9154 & 1.00 & 2.87 \\
\hline & Islamic Culture II (ISLM201) & 209 & 1.6115 & 0.41955 & 0.02902 & 1.5543 & 1.6687 & 1.00 & 2.8 \\
\hline & Islamic Culture III (ISLM301) & 186 & 1.4330 & 0.37181 & 0.02726 & 1.3792 & 1.4868 & 1.00 & 2.8 \\
\hline & $\begin{array}{l}\text { Arabic Competencies I } \\
\text { (ARABI 01) }\end{array}$ & 30 & 1.6533 & 0.51710 & 0.09441 & 1.4602 & 1.8464 & 1.00 & 2.93 \\
\hline & $\begin{array}{l}\text { Arabic Competencies II } \\
\text { (ARAB201) }\end{array}$ & 80 & 1.9675 & 0.50360 & 0.0563 & 1.8554 & 2.0796 & 1.00 & 3.00 \\
\hline & More than one course & 695 & 2.0043 & 0.45903 & 0.01741 & 1.9701 & 2.0385 & 1.00 & 3.00 \\
\hline & Total & $\mathbf{1 , 5 7 0}$ & 1.8799 & 0.49729 & 0.01255 & $\mathbf{1 . 8 5 5 3}$ & 1.9045 & 1.00 & 3.00 \\
\hline \multirow{10}{*}{$\begin{array}{l}\text { Extraneous } \\
\text { Cognitive } \\
\text { Load }\end{array}$} & $\begin{array}{l}\text { University Study Skills } \\
\text { (ETEC100) }\end{array}$ & 261 & 2.0503 & 0.49005 & 0.03033 & 1.9906 & 2.1100 & 1.00 & 3.00 \\
\hline & $\begin{array}{l}\text { Physical Fitness Skills } \\
\text { (EPHS100) }\end{array}$ & 19 & 2.0667 & 0.72009 & 0.1652 & 1.7196 & 2.4137 & 1.00 & 3.00 \\
\hline & $\begin{array}{l}\text { Entrepreneurship Skills } \\
\text { (BUS100) }\end{array}$ & 19 & 2.0456 & 0.54527 & 0.12509 & 1.7828 & 2.3084 & 1.07 & 2.87 \\
\hline & Islamic Culture I (ISLM101) & 71 & 1.6526 & 0.45884 & 0.05445 & 1.5440 & 1.7612 & 1.00 & 2.80 \\
\hline & Islamic Culture II (ISLM201) & 209 & 1.5190 & 0.47639 & 0.03295 & 1.4540 & 1.5839 & 1.00 & 3.00 \\
\hline & Islamic Culture III (ISLM301) & 186 & 1.3409 & 0.40176 & 0.02946 & 1.2827 & 1.399 & 1.00 & 2.93 \\
\hline & $\begin{array}{l}\text { Arabic Competencies I } \\
\text { (ARABI 01) }\end{array}$ & 30 & 1.7067 & 0.52365 & 0.0956 & 1.5111 & 1.9022 & 1.00 & 3.00 \\
\hline & $\begin{array}{l}\text { Arabic Competencies II } \\
\text { (ARAB201) }\end{array}$ & 80 & 1.89507 & 0.55704 & 0.06228 & 1.771 & 2.019 & 1.00 & 3.00 \\
\hline & More than one course & 695 & 1.9507 & 0.50830 & 0.01928 & 1.9128 & 1.9886 & 1.00 & 3.00 \\
\hline & Total & $\mathbf{1 , 5 7 0}$ & 1.8191 & 0.54906 & 0.01386 & 1.7919 & 1.8463 & 1.00 & 3.00 \\
\hline \multirow{4}{*}{$\begin{array}{l}\text { Total } \\
\text { Cognitive } \\
\text { Load }\end{array}$} & $\begin{array}{l}\text { University Study Skills } \\
\text { (ETEC100) }\end{array}$ & 261 & 4.1346 & 0.89141 & 0.05518 & 4.0260 & 4.2433 & 2.00 & 6.00 \\
\hline & $\begin{array}{l}\text { Physical Fitness Skills } \\
\text { (EPHS100) }\end{array}$ & 19 & 4.0421 & 1.27098 & 0.29158 & 3.4295 & 4.6547 & 2.07 & 5.93 \\
\hline & $\begin{array}{l}\text { Entrepreneurship Skills } \\
\text { (BUS100) }\end{array}$ & 19 & 4.0421 & 1.01646 & 0.23319 & 3.5522 & 4.532 & 2.13 & 5.47 \\
\hline & Islamic Culture I (ISLM101) & 71 & 3.4639 & 0.85919 & 0.10197 & 3.2605 & 3.6672 & 2.00 & 5.67 \\
\hline
\end{tabular}




\begin{tabular}{|c|c|c|c|c|c|c|c|c|}
\hline Islamic Culture II (ISLM201) & 209 & 3.1305 & 0.85688 & 0.05927 & 3.0136 & 3.2473 & 2.00 & 5.80 \\
\hline Islamic Culture III (ISLM301) & 186 & 2.7738 & 0.73191 & 0.05367 & 2.668 & 2.8797 & 2.00 & 5.40 \\
\hline $\begin{array}{l}\text { Arabic Competencies I } \\
\text { (ARABI 01) }\end{array}$ & 30 & 3.3600 & 1.00643 & 0.18375 & 2.9842 & 3.7358 & 2.00 & 5.93 \\
\hline $\begin{array}{l}\text { Arabic Competencies II } \\
\text { (ARAB201) }\end{array}$ & 80 & 3.8625 & 1.03009 & 0.11517 & 3.6333 & 4.0917 & 2.00 & 6.00 \\
\hline More than one course & 695 & 3.9550 & 0.92603 & 0.03513 & 3.8860 & 4.0240 & 2.00 & 6.00 \\
\hline Total & 1,570 & 3.6990 & 1.01044 & 0.0255 & 3.6490 & 3.7490 & 2.00 & 6.00 \\
\hline
\end{tabular}

TABLE X

ANOVA FOR COGNITIVE LOAD IN RELATION TO COURSES

\begin{tabular}{|c|c|c|c|c|c|c|}
\hline & & $\begin{array}{c}\text { Sum of } \\
\text { Squares }\end{array}$ & df & $\begin{array}{c}\text { Mean } \\
\text { Squares }\end{array}$ & $\mathbf{F}$ & Sig. \\
\hline \multirow[t]{3}{*}{ Intrinsic Cognitive Load } & Between Groups & 76.792 & 8 & 9.599 & 48.146 & .000 \\
\hline & Within Groups & 311.223 & 1561 & .199 & & \\
\hline & Total & 388.015 & 1569 & & & \\
\hline \multirow[t]{3}{*}{ Extraneous Cognitive Load } & Between Groups & 92.3030 & 8 & 11.538 & 47.309 & .000 \\
\hline & Within Groups & 380.698 & 1561 & .244 & & \\
\hline & Total & 473.000 & 1569 & & & \\
\hline \multirow[t]{3}{*}{ Total Cognitive Load } & Between Groups & 335.822 & 8 & 41.978 & 51.755 & .000 \\
\hline & Within Groups & 1266.107 & 1561 & 0.811 & & \\
\hline & Total & 1601.929 & 1569 & & & \\
\hline
\end{tabular}

The ANOVA reveals the following insights related to the research problem. The descriptive statistics and the means plot show that the highest intrinsic cognitive load on average (2.0843) is faced by students who have taken the ETEC 100 course. In comparison, the lowest intrinsic cognitive load on average (1.4330) is faced by students taking the ISLM 301 course. Consider that the ANOVA p-value is 0.000 i.e., lower than 0.05. Thus, the differences in intrinsic cognitive load faced by students in terms of course taken were statistically significant at the 5\% significance level.

Moreover, descriptive statistics and the means plot show that the highest extraneous cognitive load on average (2.0667) is faced by those students that have taken EPHS 100 course while the lowest extraneous cognitive load on average (1.3409) is faced by those students that have taken ISLM 301 course. Consider that the ANOVA p-value is 0.000 i.e., lower than 0.05 . Thus, the differences in extraneous cognitive load faced by students in terms of course taken were statistically significant at the 5\% significance level. Furthermore, descriptive statistics and the means plot show that the highest total cognitive load on average (4.1346) is faced by those students that have taken ETEC 100 course while the lowest total cognitive load on average (2.7738) is faced by those students that have taken ISLM 301 course. Consider that the ANOVA p-value is 0.000 lower than 0.05. Thus, the differences in total cognitive load faced by students in terms of course taken were statistically significant at the $5 \%$ significance level.

\section{b) The Effect of Gender on Cognitive Load Level}

This research problem could be answered using ANOVA only. Curve estimation or regression could not have been used in this case because 'gender' is a categorical variable instead of an ordinal one, and thus regression coefficient would have no meaningful interpretation. The ANOVA can be seen in Table XI and Table XII.

TABLE XI

THE MEAN AND SD FOR GENDER AND COGNITIVE LOAD

\begin{tabular}{|c|c|c|c|c|c|c|c|c|c|}
\hline & \multirow[t]{2}{*}{ Gender } & \multirow[t]{2}{*}{$\mathbf{N}$} & \multirow[t]{2}{*}{ Mean } & \multirow[t]{2}{*}{$\begin{array}{c}\text { Std. } \\
\text { Deviation }\end{array}$} & \multirow[t]{2}{*}{$\begin{array}{l}\text { Std. } \\
\text { Error }\end{array}$} & \multicolumn{2}{|c|}{$\begin{array}{l}\text { 95\% Confidence } \\
\text { Interval for Mean }\end{array}$} & \multirow[t]{2}{*}{ Minimum } & \multirow[t]{2}{*}{ Maximum } \\
\hline & & & & & & $\begin{array}{l}\text { Lower } \\
\text { Bound }\end{array}$ & $\begin{array}{l}\text { Upper } \\
\text { Bound }\end{array}$ & & \\
\hline \multirow{3}{*}{$\begin{array}{l}\text { Q6 Intrinsic } \\
\text { Cognitive Load }\end{array}$} & Male & 589 & 1.9116 & 0.48897 & 0.02015 & 1.8720 & 1.9512 & 1.00 & 3.00 \\
\hline & Female & 981 & 1.8608 & 0.50151 & 0.01601 & 1.8294 & 1.8922 & 1.00 & 3.00 \\
\hline & Total & 1,570 & 1.8799 & 0.49729 & 0.01255 & 1.8553 & 1.9045 & 1.00 & 3.00 \\
\hline \multirow{3}{*}{$\begin{array}{l}\text { Q7 Extraneous } \\
\text { Cognitive Load }\end{array}$} & Male & 589 & 1.8626 & 0.54415 & 0.02242 & 1.8186 & 1.9066 & 1.00 & 3.00 \\
\hline & Female & 981 & 1.7930 & 0.55061 & 0.01758 & 1.7585 & 1.8275 & 1.00 & 3.00 \\
\hline & Total & 1,570 & 1.8191 & 0.54906 & 0.01386 & 1.7919 & 1.8463 & 1.00 & 3.00 \\
\hline \multirow[t]{3}{*}{ Total Cognitive Load } & Male & 589 & 3.7742 & 0.99340 & 0.04093 & 3.6938 & 3.8546 & 2.00 & 6.00 \\
\hline & Female & 981 & 3.6538 & 1.01837 & 0.03251 & 3.5900 & 3.7176 & 2.00 & 6.00 \\
\hline & Total & 1,570 & 3.6990 & 1.01044 & 0.02550 & 3.6490 & 3.7490 & 2.00 & 6.00 \\
\hline
\end{tabular}


TABLE XII

ANOVA FOR COGNITIVE LOAD IN RELATION TO GENDER

\begin{tabular}{|c|c|c|c|c|c|c|}
\hline & & $\begin{array}{c}\text { Sum of } \\
\text { Squares }\end{array}$ & df & $\begin{array}{c}\text { Mean } \\
\text { Squares }\end{array}$ & $\mathbf{F}$ & Sig. \\
\hline \multirow[t]{3}{*}{ Intrinsic Cognitive Load } & Between Groups & 0.949 & 1 & 0.949 & \multirow[t]{3}{*}{3.845} & \multirow[t]{3}{*}{0.50} \\
\hline & Within Groups & 387.066 & 1568 & 0.247 & & \\
\hline & Total & 388.015 & 1569 & & & \\
\hline \multirow[t]{3}{*}{ Extraneous Cognitive Load } & Between Groups & 1.782 & 1 & 1.782 & \multirow[t]{3}{*}{5.931} & \multirow[t]{3}{*}{0.15} \\
\hline & Within Groups & 471.218 & 1568 & 0.301 & & \\
\hline & Total & 473.000 & 1569 & & & \\
\hline \multirow[t]{3}{*}{ Total Cognitive Load } & Between Groups & 5.333 & 1 & 5.333 & \multirow[t]{3}{*}{5237} & \multirow[t]{3}{*}{0.22} \\
\hline & Within Groups & 1596.596 & 1568 & 1.018 & & \\
\hline & Total & 1601.929 & 1569 & & & \\
\hline
\end{tabular}

The ANOVA reveals the following insights related to the research problem. The descriptive statistics and the means plot show that male students face the highest intrinsic cognitive load on average (1.9116). Consider that the ANOVA p-value is 0.05 i.e., equal to 0.05 . Thus, the differences in intrinsic cognitive load faced by students in terms of gender were statistically significant at the 5\% significance level. Moreover, descriptive statistics and the means plot show that male students face the highest extraneous cognitive load on average (1.8626). Consider that the ANOVA p-value is 0.015 i.e., lower than 0.05 . Thus, the differences in extraneous cognitive load faced by students in terms of gender were statistically significant at the 5\% significance level.

Furthermore, descriptive statistics and the means plot show that male students face the highest total cognitive load on average (3.7742). Consider that the ANOVA p-value is 0.022 i.e., lower than 0.05 . Thus, the differences in total cognitive load faced by students in terms of gender were statistically significant at the $5 \%$ significance level.

c) The Effect of Age on Cognitive Load Level Age and intrinsic cognitive load

This research problem could be answered using ANOVA and curve estimation. It is noted that curve estimation or regression could be used in this case because the independent variable 'age' is a continuous variable. The ANOVA for the impact of age on intrinsic cognitive load can be seen in Table XIII. According to Table XIV, there is a statistically significant difference in intrinsic cognitive load faced by people of different age groups as a p-value of 0.000 is less than 0.05 .

TABLE XIII

THE MEAN AND SD OF AGE AND COGNITIVE LOAD

\begin{tabular}{|c|c|c|c|c|c|c|c|c|}
\hline & \multirow[b]{2}{*}{$\mathbf{N}$} & \multirow[b]{2}{*}{ Mean } & \multirow{2}{*}{$\begin{array}{c}\text { Std. } \\
\text { Deviation }\end{array}$} & \multirow{2}{*}{$\begin{array}{c}\text { Std. } \\
\text { Error }\end{array}$} & \multicolumn{2}{|c|}{$\begin{array}{c}\text { 95\% Confidence Interval for } \\
\text { Mean }\end{array}$} & \multirow[b]{2}{*}{ Minimum } & \multirow[b]{2}{*}{ Maximum } \\
\hline & & & & & Lower Bound & Upper Bound & & \\
\hline 18.00 & 83 & 2.0394 & .43679 & .4794 & 1.9440 & 2.1347 & 1.07 & 3.00 \\
\hline 19.00 & 448 & 2.0951 & .43386 & .02050 & 2.0548 & 2.1354 & 1.00 & 3.00 \\
\hline 20.00 & 370 & 1.9126 & .45636 & .02373 & 1.8660 & 1.9593 & 1.00 & 3.00 \\
\hline 21.00 & 265 & 1.7082 & .49186 & .03021 & 1.6487 & 1.7677 & 1.00 & 3.00 \\
\hline 22.00 & 189 & 1.7097 & .53584 & .03898 & 1.6328 & 1.7866 & 1.00 & 3.00 \\
\hline 23.00 & 114 & 1.6439 & .45939 & .04303 & 1.5586 & 1.7291 & 1.07 & 3.00 \\
\hline 24.00 & 31 & 1.5871 & .41754 & .07499 & 1.4339 & 1.7403 & 1.07 & 2.73 \\
\hline 25.00 & 10 & 1.4000 & .37974 & .12008 & 1.1284 & 1.6716 & 1.00 & 2.20 \\
\hline 26.00 & 5 & 1.7600 & 62289 & .27857 & .9866 & 2.5334 & 1.20 & 2.73 \\
\hline 28.00 & 1 & 2.2000 & & & & & 2.20 & 2.20 \\
\hline 30.00 & 6 & 1.9222 & .46268 & .18889 & 1.4367 & 2.4078 & 1.33 & 2.60 \\
\hline 32.00 & 2 & 1.8667 & .09426 & .06665 & 1.0198 & 2.7135 & 1.80 & 1.93 \\
\hline 39.00 & 1 & 1.8000 & & & & & 1.80 & 1.80 \\
\hline Total & 1,525 & 1.8820 & .49640 & .01271 & 1.8570 & 1.9069 & 1.00 & 3.00 \\
\hline
\end{tabular}

TABLE XIV

ANOVA FOR COGNITIVE LOAD IN RELATION TO AGE

\begin{tabular}{lccccc}
\hline & Sum of Squares & df & Mean Square & F & Sig. \\
\hline Between Groups & 48.039 & 12 & 4.003 & 18.483 & .000 \\
Within Groups & 327.488 & 1512 & .217 & & \\
\cline { 1 - 4 } Total & $\mathbf{3 7 5 . 5 2 7}$ & $\mathbf{1 5 2 4}$ & & \\
\hline
\end{tabular}


The quadratic model has the highest R-squared (i.e., 0.107). This implies that the relationship between age and intrinsic cognitive load is best described as 'quadratic.' The regression equation can be seen in equation (4).

Intrinsic cognitive load $=7.650-0.455 * A g e+0.008 * \mathrm{Age}^{2}(4)$
This implies that a rise in age initially leads to a fall in intrinsic cognitive load, but after a certain age (i.e., 27), a rise in age leads to a rise in intrinsic cognitive load.

\section{Age and Extraneous Cognitive Load}

The ANOVA for the impact of age on extraneous cognitive load can be seen in Table XV. Age with highest to lowest extraneous cognitive load is listed in Table XVI.

TABLE XV

THE MEAn AND SD of AgE AND ExTRANEous Cognitive LOAD

\begin{tabular}{|c|c|c|c|c|c|c|c|c|}
\hline & \multirow[b]{2}{*}{$\mathbf{N}$} & \multirow[b]{2}{*}{ Mean } & \multirow{2}{*}{$\begin{array}{c}\text { Std. } \\
\text { Deviation }\end{array}$} & \multirow{2}{*}{$\begin{array}{l}\text { Std. } \\
\text { Error }\end{array}$} & \multicolumn{2}{|c|}{$\begin{array}{l}\text { 95\% Confidence Interval for } \\
\text { Mean }\end{array}$} & \multirow[b]{2}{*}{ Minimum } & \multirow[b]{2}{*}{ Maximum } \\
\hline & & & & & Lower Bound & Upper Bound & & \\
\hline 18.00 & 83 & 1.9807 & .46939 & .05152 & 1.8782 & 2.0832 & 1.07 & 3.00 \\
\hline 19.00 & 448 & 2.0451 & .48371 & .02285 & 2.0002 & 2.0900 & 1.00 & 3.00 \\
\hline 20.00 & 370 & 1.8409 & .52252 & .02716 & 1.7875 & 1.8943 & 1.00 & 3.00 \\
\hline 21.00 & 235 & 1.6332 & .53157 & .03265 & 1.5689 & 1.6975 & 1.00 & 3.00 \\
\hline 22.00 & 189 & 1.6501 & .56959 & .04143 & 1.5684 & 1.7318 & 1.00 & 3.00 \\
\hline 23.00 & 114 & 1.5854 & .54858 & .05138 & 1.4836 & 1.6872 & 1.00 & 3.00 \\
\hline 24.00 & 31 & 1.5075 & 40939 & .07353 & 1.3574 & 1.6577 & 1.00 & 2.47 \\
\hline 25.00 & 10 & 1.5533 & .53337 & .16867 & 1.1718 & 1.9349 & 1.00 & 2.40 \\
\hline 26.00 & 5 & 1.7867 & .5933 & .26533 & 1.0500 & 2.5234 & 1.00 & 2.60 \\
\hline 28.00 & 1 & 2.0667 & & & & & 2.07 & 2.07 \\
\hline 30.00 & 6 & 1.7556 & .57142 & .23328 & 1.1559 & 2.3552 & 1.00 & 2.47 \\
\hline 32.00 & 2 & 1.7000 & .04709 & .0333 & 1.2769 & 2.1231 & 1.67 & 1.73 \\
\hline 39.00 & 1 & 1.6667 & & & & & 1.67 & 1.67 \\
\hline Total & 1,525 & 1.8203 & .5455 & .01397 & 1.7929 & 1.8477 & 1.00 & 3.00 \\
\hline
\end{tabular}

TABLE XVI

ANOVA FOR EXTRANEOUS COGNITIVE LOAD IN RELATION TO AGE

\begin{tabular}{lccccc}
\hline & Sum of Squares & df & Mean Square & F & Sig. \\
\hline Between Groups & 49.863 & 12 & 4.155 & 15.566 & .000 \\
Within Groups & 403.627 & 1512 & .267 & & \\
\cline { 1 - 4 } Total & $\mathbf{4 5 3 . 4 9 0}$ & $\mathbf{1 5 2 4}$ & & & \\
\hline
\end{tabular}

There is a statistically significant difference in the extraneous cognitive load faced by people of different age groups as a p-value of 0.000 is less than 0.05 . The $S$ model has the highest R-squared (i.e., 0.093). This implies that the relationship between age and extraneous cognitive load is best described as 'S-curve.' The regression equation can be seen in equation (5).

$\operatorname{Ln}($ Extraneous cognitive load $)=-0.695+\frac{24.620}{\text { Age }}$
This implies that a rise in age leads to a fall in extraneous cognitive load but at a decreasing rate.

\section{Age and Total Cognitive Load}

The ANOVA for the impact of age on total cognitive load can be seen in Table XVII. Age with highest to lowest total cognitive load is listed in Table XVIII.

TABLE XVII

THE MEAN AND SD FOR AGE AND TOTAL COGNITIVE LOAD

\begin{tabular}{ccccccrr}
\hline & & & & & \multicolumn{2}{c}{ 95\% Confidence Interval for } \\
Mean
\end{tabular}




\begin{tabular}{lcccccccc}
25.00 & 10 & 2.9533 & .88891 & .28110 & 2.3174 & 3.5892 & 2.00 & 4.53 \\
26.00 & 5 & 3.5467 & 1.19851 & .53599 & 2.0585 & 5.0348 & 2.20 & 4.33 \\
28.00 & 1 & 4.2667 & & & & & 4.27 & 4.27 \\
30.00 & 6 & 3.6778 & 1.01320 & .41364 & 2.6145 & 3.7411 & 3.53 & 3.60 \\
32.00 & 2 & 3.5667 & .04716 & .03335 & 3.1429 & 3.9904 & 3.47 & 3.47 \\
39.00 & 1 & 3.4667 & & & & & $\mathbf{3 . 7 5 2 8}$ & $\mathbf{2 . 0 0}$ \\
\hline Total & $\mathbf{1 , 5 2 5}$ & $\mathbf{3 . 7 0 2 3}$ & $\mathbf{1 . 0 0 5 9 0}$ & $\mathbf{. 0 2 5 7 6}$ & $\mathbf{3 . 6 5 1 8}$ & $\mathbf{6 . 0 0}$ \\
\hline
\end{tabular}

TABLE XVIII

ANOVA FOR AGE AND TOTAL COGNITIVE LOAD

\begin{tabular}{lcccc}
\hline & Sum of Squares & df & Mean Square & F \\
\hline Between Groups & 195.045 & 12 & 16.254 & 18.245 \\
Within Groups & 1346.988 & 1512 & .891 & .000 \\
\hline Total & $\mathbf{1 5 4 2 . 0 3 2}$ & $\mathbf{1 5 2 4}$ & & \\
\hline
\end{tabular}

There is a statistically significant difference in total cognitive load faced by people of different age groups as a pvalue of 0.000 is less than 0.05 . The quadratic model has the highest R-squared (i.e., 0.105). This implies that the relationship between age and total cognitive load is best described as 'quadratic.' The regression equation can be seen in equation (6).

Total cognitive load $=15.192-0.905 * A g e+0.017 * A g e^{2}$

This implies that a rise in age initially leads to a fall in total cognitive load, but after a certain age (i.e., 27), a rise in age leads to a rise in total cognitive load.

\section{d) The Effect of Age on Cognitive Load Level}

This research problem could be answered using ANOVA and curve estimation. It is obvious that curve estimation or regression could be used in this case because the independent variable 'GPA' is a continuous variable. The highest intrinsic cognitive load is associated with a GPA of 3.82 and the lowest cognitive load is associated with a GPA of 3.57. ANOVA for GPA and intrinsic cognitive load can be seen in Table XIX.

TABLE XIX

ANOVA FOR GPA AND INTRINSIC COGNITIVE LOAD

\begin{tabular}{lrrrrr}
\hline & $\begin{array}{c}\text { Sum of } \\
\text { Squares }\end{array}$ & \multicolumn{1}{c}{ df } & $\begin{array}{c}\text { Mean } \\
\text { Square }\end{array}$ & F & \multicolumn{1}{c}{ Sig. } \\
\cline { 1 - 5 } Between Groups & 67.559 & 248 & .272 & 1.123 & .111 \\
Within Groups & 320.456 & 1321 & .243 & & \\
\cline { 1 - 4 } Total & $\mathbf{3 8 8 . 0 1 5}$ & $\mathbf{1 5 6 9}$ & & & \\
\hline
\end{tabular}

The differences in intrinsic cognitive load students face of different GPAs are statistically insignificant since the p-value of 0.111 is higher than 0.05 . The cubic model has the highest R-squared (i.e., 0.010). This implies that the relationship between GPA and intrinsic cognitive load is best described as 'cubic.' The regression equation can be seen in equation (7).

Intrinsic cognitive load $=2.447-0.224 * G P A-0.012 * G P A^{2}+$ $0.007 * G P A^{3}$

Initially, a rise in GPA leads to a fall in intrinsic cognitive load, but after a certain GPA (i.e., 4), a rise in GPA leads to a rise in intrinsic cognitive load. The highest extraneous cognitive load is associated with the GPA of 4.99 and the lowest cognitive load is associated with a GPA of 4.92 . ANOVA for GPA and extraneous cognitive load can be seen in Table XX.

TABLE XX

ANOVA FOR GPA AND EXTRANEOUS COGNITIVE LOAD

\begin{tabular}{lrrrrr}
\hline & $\begin{array}{c}\text { Sum of } \\
\text { Squares }\end{array}$ & \multicolumn{1}{c}{ df } & $\begin{array}{c}\text { Mean } \\
\text { Square }\end{array}$ & F & \multicolumn{1}{c}{ Sig. } \\
\cline { 1 - 5 } Between Groups & 86.567 & 248 & .349 & 1.193 & .031 \\
Within Groups & 386.433 & 1321 & .293 & & \\
\cline { 1 - 5 } Total & $\mathbf{4 7 3 . 0 0 0}$ & $\mathbf{1 5 6 9}$ & & & \\
\hline
\end{tabular}

The differences in the extraneous cognitive load faced by students of different GPAs are statistically significant since the p-value of 0.031 is lower than 0.05 . The cubic model has the highest R-squared (i.e., 0.011). This implies that the relationship between GPA and extraneous cognitive load is best described as 'cubic.' The regression equation can be seen in equation (8). Extraneous cognitive load $=2.212-0.056 * G P A$
$0.068 * G P A^{2}+0.014 * G P A^{3}$

Initially, a rise in GPA leads to a fall in extraneous cognitive load, but after a certain GPA (i.e., 4) a rise in GPA leads to a rise in extraneous cognitive load. The highest total cognitive load is associated with a GPA of 4.99 and the lowest cognitive load is associated with a GPA of 3.57. ANOVA for GPA and total cognitive load can be seen in Table XXI.

TABLE XXI

ANOVA FOR GPA AND TOTAL COGNITIVE LOAD

\begin{tabular}{lrrrrr}
\hline & $\begin{array}{c}\text { Sum of } \\
\text { Squares }\end{array}$ & df & $\begin{array}{r}\text { Mean } \\
\text { Square }\end{array}$ & F & \multirow{2}{*}{ Sig. } \\
\cline { 1 - 4 } Between Groups & 287.811 & 248 & 1.161 & 1.167 & .052 \\
Within Groups & 1314.118 & 1321 & .995 & & \\
\cline { 1 - 5 } Total & $\mathbf{1 6 0 1 . 9 2 9}$ & $\mathbf{1 5 6 9}$ & & & \\
\hline
\end{tabular}

The differences in total cognitive load students face of different GPAs are statistically insignificant since the p-value of 0.052 is higher than 0.05 . The cubic model has the highest R-squared (i.e., 0.11). This implies that the relationship 
between GPA and total cognitive load is best described as 'cubic.' The regression equation can be seen in equation (9).

Total cognitive load $=4.659-0.280 * G P A-0.080 * G P A^{2}+$ $0.021 * G P A^{3}$

Initially, a rise in GPA leads to a fall in total cognitive load, but after a certain GPA (i.e., 4) a rise in GPA leads to a rise in total cognitive load.

3) The Effect of Device Screen Size on Intrinsic and Extraneous Cognitive Load Influenced by Gender and/or Course a) The Effect of Device Screen Size on Intrinsic Cognitive Load Influenced by Gender and/or Course

The R-squared change is positive in the below model summary (see Table XXII). This implies that impact of device screen size on intrinsic cognitive load depends upon gender. The R-squared change is negligible in the below model summary (see Table XXIII). This implies that impact of device screen size on intrinsic cognitive load does not depend upon course taken.

TABLE XXII

MODEL SUMMARY FOR SCREEN SIZE AND GENDER

\begin{tabular}{|c|c|c|c|c|c|c|c|c|c|}
\hline \multirow[b]{2}{*}{ Model } & \multirow[b]{2}{*}{$\mathbf{R}$} & \multirow[b]{2}{*}{ R Square } & \multirow[b]{2}{*}{$\begin{array}{l}\text { Adjusted } \\
\text { R Square }\end{array}$} & \multirow[b]{2}{*}{$\begin{array}{l}\text { Std. Error of } \\
\text { the Estimate }\end{array}$} & \multicolumn{5}{|c|}{ Change Statistics } \\
\hline & & & & & $\begin{array}{l}\text { R Square } \\
\text { Change }\end{array}$ & F Change & df1 & df2 & $\begin{array}{c}\text { Sig. F } \\
\text { Change }\end{array}$ \\
\hline 1 & $.029^{\mathrm{a}}$ & .001 & .000 & .49724 & .001 & 1.363 & 1 & 1568 & .243 \\
\hline 2 & $.061^{\mathrm{b}}$ & .004 & .002 & .49669 & .003 & 4.433 & 1 & 1567 & .035 \\
\hline
\end{tabular}

TABLE XXIII

MODEL SUMMARY FOR SCREEN SIZE AND COURSE

\begin{tabular}{|c|c|c|c|c|c|c|c|c|c|}
\hline \multirow[b]{2}{*}{ Model } & \multirow[b]{2}{*}{$\mathbf{R}$} & \multirow[b]{2}{*}{ R Square } & \multirow[b]{2}{*}{$\begin{array}{c}\text { Adjusted R } \\
\text { Square }\end{array}$} & \multirow[b]{2}{*}{$\begin{array}{l}\text { Std. Error of } \\
\text { the Estimate }\end{array}$} & \multicolumn{5}{|c|}{ Change Statistics } \\
\hline & & & & & $\begin{array}{c}\text { R Square } \\
\text { Change }\end{array}$ & F Change & df1 & df2 & $\begin{array}{c}\text { Sig. F } \\
\text { Change }\end{array}$ \\
\hline 1 & $.029^{\mathrm{a}}$ & .001 & .000 & .49724 & .001 & 1.363 & 1 & 1568 & .243 \\
\hline 2 & $.035^{\mathrm{b}}$ & .001 & .000 & .49731 & .000 & .551 & 1 & 1567 & .458 \\
\hline
\end{tabular}

a. Predictors: (Constant), Q3 Screensize

b. Predictors: (Constant), Q3_Screensize, Screensize_course

b) The Effect of Device Screen Size on Extraneous Cognitive Load Influenced by Gender and/or Course

The R-squared change is positive in the below model summary (see Table XXIV). This implies that impact of device screen size on extraneous cognitive load depends upon gender. The R-squared change is negligible in the below model summary (see Table XXV). This implies that impact of device screen size on extraneous cognitive load does not depend upon course taken.

TABLE XXIV

MODEL SUMMARY FOR SCREEN SIZE AND GENDER

\begin{tabular}{|c|c|c|c|c|c|c|c|c|c|}
\hline \multirow[b]{2}{*}{ Model } & \multirow[b]{2}{*}{$\mathbf{R}$} & \multirow[b]{2}{*}{ R Square } & \multirow[b]{2}{*}{$\begin{array}{l}\text { Adjusted R } \\
\text { Square }\end{array}$} & \multirow[b]{2}{*}{$\begin{array}{l}\text { Std. Error of } \\
\text { the Estimate }\end{array}$} & \multicolumn{5}{|c|}{ Change Statistics } \\
\hline & & & & & $\begin{array}{l}\text { R Square } \\
\text { Change }\end{array}$ & F Change & df1 & df2 & $\begin{array}{l}\text { Sig. F } \\
\text { Change }\end{array}$ \\
\hline 1 & $.048^{\mathrm{a}}$ & .002 & .002 & .54859 & .002 & 3.665 & 1 & 1568 & .056 \\
\hline 2 & $.081^{\mathrm{b}}$ & .007 & .005 & .54760 & .004 & 6.692 & 1 & 1567 & .010 \\
\hline
\end{tabular}

a. Predictors: (Constant), Q3_Screensize

b. Predictors: (Constant), Q3_Screensize, Screensize_gender

TABLE XXV

MODEL SUMMARY FOR SCREEN SIZE AND COURSE

\begin{tabular}{|c|c|c|c|c|c|c|c|c|c|}
\hline \multirow[b]{2}{*}{ Model } & \multirow[b]{2}{*}{$\mathbf{R}$} & \multirow[b]{2}{*}{ R Square } & \multirow[b]{2}{*}{$\begin{array}{c}\text { Adjusted R } \\
\text { Square }\end{array}$} & \multirow[b]{2}{*}{$\begin{array}{l}\text { Std. Error of } \\
\text { the Estimate }\end{array}$} & \multicolumn{5}{|c|}{ Change Statistics } \\
\hline & & & & & $\begin{array}{l}\text { R Square } \\
\text { Change }\end{array}$ & F Change & df1 & df2 & $\begin{array}{c}\text { Sig. F } \\
\text { Change }\end{array}$ \\
\hline 1 & $.048^{\mathrm{a}}$ & .002 & .002 & .54859 & .002 & 3.665 & 1 & 1568 & .056 \\
\hline 2 & $.049^{\mathrm{b}}$ & .002 & .001 & .54874 & .000 & .149 & 1 & 1567 & .700 \\
\hline
\end{tabular}

a. Predictors: (Constant), Q3 Screensize

b. Predictors: (Constant), Q3_Screensize, Screensize_course 


\section{B. Discussion}

The first finding of this research questions revealed that the effect of screen size on intrinsic cognitive load is direct, which means that increasing the size of the screen leads to an increase in cognitive load; small screens thus produce the lowest intrinsic cognitive load. However, in 5.1.2. the findings have suggested that the lowest extraneous cognitive load i.e. 1.7549 (average) is faced by students having small screen smartphones i.e. 4 inches. This reduction in extraneous cognitive load is interpreted by the small size of presenting information. These small screens accommodate small chunks of projecting information (Sweller, 1988). Screen size plays the main role in the experience quality of mobile learning and this agrees with Trivason \& Krathu (2017). The result in section 5.1.3 shows that small screen size is the best i.e. 4 inches, as it creates the lowest total cognitive load i.e. 3.51 (average), as ANOVA p-value is 0.024. As per Wang et al. (2013). The larger display screens did produce more attitude towards the material as well as increasing the readability. However, the scope of this paper is only concerning about cognitive load not like Wang et al.'s (2013) study where they have a broader scope that include user attitude and interest. Hence, with regards to cognitive load, small screen smartphones are the best. Karam (2015) pointed out that screen size does not affect cognitive load and learning outcomes, and this research showed otherwise, as based on statistical methodologies adopted widely and directly from the data of students. This research results suggested the findings on the ground of cognitive load measurement.

In section 5.2.1 the effect of courses and cognitive load is measured. As it is a categorical variable, it shows that the change of course from ETEC 100 to EPHS 100 has led to a change in cognitive load. The lowest cognitive load is faced by the students who choose ISLM 301 course. The students who participate in this research belongs to a Saudi culture which is an Islamic one and this explains their interest in the course. Hence, in comparison to advanced subjects, the least cognitive load was for students who were already aware with the course i.e. concepts, created the least cognitive load i.e. ANOVA p-value is 0.000 . "Courses" is a categorical variable and screen size is an ordinal variable, so it cannot be calculated but roughly measured.

In section 5.2.2, the relation between gender and cognitive load is analyzed, and it has been shown that gender is a categorical variable, unlike cognitive load which is ordinal. The results reported that males faced higher intrinsic, extraneous, and total cognitive load i.e. 1.9116. There could be many factors behind this. Psychologically, the male brain is involved in more social and professional thoughts comparatively than women. This is also explained by the fact that the research is conducted in Saudi Arabia and females are not participating directly in running the country's economy. This answer can vary demographically from one place to another.

In section 5.2.3, the age relationship with the cognitive load level is tested. Interestingly, this result shows that a rise in age initially leads to a drop in total cognitive load but after a certain age i.e. 27 it also starts rising. Kim \& Kim (2012) agrees with the findings as advancing with age after a certain period leads to a diminishing rate in the growth of brain cells as it does earlier.

In section 5.2.4, the association of GPA with cognitive load is analyzed. The result shows that an initial rise in GPA leads to a fall in cognitive load, but later students with the highest GPA i.e. 3.82, faced the highest cognitive load and then the lowest cognitive load is associated with GPA i.e. 3.57. Whereas in section 5.3, the impact of device screen size on intrinsic cognitive load and its relationship with gender and courses taken is analyzed, all together. The results ultimately revealed that as far as gender is concerned, intrinsic cognitive load depends upon gender but not on the course taken. The research findings are broad and clear as per the statistical methodologies used for data collection. The results reflect the transparency by showing that smartphone with a small screen size is the best as they release the least cognitive load. However, large screen size of smartphones causes the most cognitive load, especially during M-learning. Overall, the research findings revealed the importance of cognitive load regarding academic and educational activities in a diversified and precise manner.

\section{CONClusions}

M-learning introduces a new scope of education for the world. It is more convenient, easy to access, and efficient for both teachers and students. However, modernized innovations are new enough to deal and cope with the effects and psychological measures to ensure better effectiveness in the provision of information and knowledge. The research has seen the impact of cognitive load on M-learning from the ground level. It has been shown that students having smartphones with small screen sizes get the least cognitive load, followed by large-screen tablet users who get the second least cognitive load, whereas the small-screen tablets and large screen smartphones create the most cognitive load. On the other hand, students have a great impact of cognitive load on their performance and efficiency, according on the findings, students having small screen size smartphones got the lowest cognitive load. As far the GPA is concerned, students with the lowest GPA and highest GPA experienced the most cognitive load, which is a relatable factor of psychology. The studies suggest that age also contributes to the resistance or support to cognitive load, with the progress in age, cognitive load falls but up to a certain level i.e. 27 years. After that, cognitive load is found surging with the increase in age.

Data gathered by this paper highly suggest that male students got the highest cognitive load in comparison to female students. Surprisingly, this is a demographic based finding and could vary at this point as per the geographic location. The recommendation, however, is that research can be carried further focusing on the impact of cognitive load and effective M-learning strategies. This can ultimately increase the productivity and development of the world, wherever the M-learning technology is been exposed and applied. 


\section{REFERENCES}

Alalwan, A. A., Baabdullah, A. M., Rana, N. P., Tamilmani, K., \& Dwivedi, Y. K. (2018). Examining adoption of mobile internet in Saudi Arabia: Extending TAM with perceived enjoyment, innovativeness and trust. Technology in Society, 55, 100-110. doi:https://doi.org/10.1016/j.techsoc.2018.06.007

Anderson, E. K. (2013). Mobile Learning. In R. Richey (Ed.), Encyclopedia of terminology for educational communications and technology (pp. 214-215). NY: Springer.

Badawi, Z. (2014). miqyas aleib' almaerifii [Cognitive Load Scale]. Cairo: Dar Al-Ketab Alhadeeth.

Brunken, R., Plass, J. L., \& Leutner, D. (2003). Direct measurement of cognitive load in multimedia learning. Educational Psychologist, 38(1), 53-61.

Brünken, R., Plass, J. L., \& Leutner, D. (2004). Assessment of Cognitive Load in Multimedia Learning with DualTask Methodology: Auditory Load and Modality Effects. Instructional Science, 32(1), 115-132. doi:10.1023/B:TRUC.0000021812.96911.c5

Byrd, K. S., \& Caldwell, B. S. (2011). Increased memory load during task completion when procedures are presented on mobile screens. Behaviour \& Information Technology, 30(5), 643-658. doi:10.1080/0144929X.2010.529944

Castro, S. (2017). How Handheld Mobile Device Size and Hand Location May Affect Divided Attention.

Chae, M., \& Kim, J. (2004). Do size and structure matter to mobile users? An empirical study of the effects of screen size, information structure, and task complexity on user activities with standard web phones. Behaviour \& Information Technology, 23(3), 165-181. doi:10.1080/01449290410001669923

Chang, C. C., Lei, H., \& Tseng, J. S. (2011). Media presentation mode, English listening comprehension and cognitive load in ubiquitous learning environments: Modality effect or redundancy effect? Australasian journal of educational technology, 27(4), 633-654.

Chee, K. N., Yahaya, N., Ibrahim, N. H., \& Hasan, M. N. (2017). Review of Mobile Learning Trends 20102015: A Meta-Analysis. Journal of Educational Technology \& Society, 20(2), 113-126.

Chen, J. (2010, 30-31 May). Reducing cognitive load in mobile learning: Activity-centered perspectives. Paper presented at the Networking and Digital Society (ICNDS), 2010 2nd International Conference on.

Cheng, P.-Y., Huang, Y.-M., Shadiev, R., Hsu, C.-W., \& Chu, S.-T. (2014). Investigating the Effectiveness of Video Segmentation on Decreasing Learners' Cognitive Load in Mobile Learning. In Y. Cao, T. Väljataga, J. K. T. Tang, H. Leung, \& M. Laanpere (Eds.), New Horizons in Web Based Learning (Vol. 8699, pp. 122-129): Springer International Publishing.

Cross, L. H., \& Belli, G. M. (2004). Experimental research to inform educational policy. In K. deMarrais \& S. D.
Lapan (Eds.), Foundations for Research: Methods of Inquiry in Education and the Social Sciences (pp. 329). Mahwah, NJ: Lawrence Erlbaum Associates.

Deegan, R. (2015). Complex Mobile Learning that Adapts to Learners' Cognitive Load. International Journal of Mobile and Blended Learning (IJMBL), 7(1), 13-24. doi:10.4018/ijmbl.2015010102

Furió, D., González-Gancedo, S., Juan, M. C., Seguí, I., \& Costa, M. (2013). The effects of the size and weight of a mobile device on an educational game. Computers \& Education, 64, 24-41. doi:10.1016/j.compedu.2012.12.015

Ghamdi, E., Yunus, F., Da'ar, O., El-Metwally, A., Khalifa, M., Aldossari, B., \& Househ, M. (2015). The Effect of Screen Size on Mobile Phone User Comprehension of Health Information and Application Structure: An Experimental Approach. Journal of medical systems, 40, 11. doi:10.1007/s10916-015-0381-5

Hou, J., Nam, Y., Peng, W., \& Lee, K. (2012). Effects of screen size, viewing angle, and players' immersion tendencies on game experience. Computers in Human Behavior, 28, 617-623. doi:10.1016/j.chb.2011.11.007

Hu, C.-Y., Lin, H.-Y., \& Chen, L.-C. (2016). The effects of screen size on rotating 3D contents using compound gestures on a mobile device. Displays, 41, 25-32. doi:https://doi.org/10.1016/j.displa.2015.11.002

Hwang, G.-J., Wu, P.-H., Zhuang, Y.-Y., Kuo, W.-L., \& Huang, Y.-M. (2010, 12-16 April). An Investigation on Students' Cognitive Load and Learning Achievements for Participating in a Local Culture Mobile Learning Activity. Paper presented at the Wireless, Mobile and Ubiquitous Technologies in Education (WMUTE), 2010 6th IEEE International Conference on.

Karam, A. (2015). A comparison of the effects of mobile device display size and orientation, and text segmentation on learning, cognitive load, and user perception in a higher education chemistry course.

Kim, D., \& Kim, D.-J. (2012). Effect of screen size on multimedia vocabulary learning. British Journal of Educational Technology, 43, 62-70. doi:10.1111/j.1467-8535.2010.01145.x

Kim, K. J., \& Sundar, S. S. (2014). Does screen size matter for smartphones? Utilitarian and hedonic effects of screen size on smartphone adoption. Cyberpsychology, behavior and social networking, 17. doi:10.1089/cyber.2013.0492

Kim, K. J., \& Sundar, S. S. (2016). Mobile persuasion: Can screen size and presentation mode make a difference to trust? Human Communication Research, 42, 45-70. doi:10.1111/hcre.12064

Klepsch, M., Schmitz, F., \& Seufert, T. (2017). Development and Validation of Two Instruments Measuring Intrinsic, Extraneous, and Germane Cognitive Load. Frontiers in Psychology, 8 doi:10.3389/fpsyg.2017.01997 
Liu, T.-C., Lin, Y.-C., \& Paas, F. (2013). Effects of Cues and Real Objects on Learning in a Mobile Device Supported Environment. British Journal of Educational Technology, 44(3), 386.

Nipan, M., Emily, B., Hand, S., \& George, A. (2008). The Effect of Mobile Phone Screen Size on Video Based Learning. Journal of Software, 3. doi:10.4304/jsw.3.4.51-61

Paas, F., Tuovinen, J., Tabbers, H., \& Van Gerven, P. (2003). Cognitive Load Measurement as a Means to Advance Cognitive Load Theory. Educational Psychologist Educ Psychol, 38, 63-71. doi:10.1207/S15326985EP3801_8

Paas, F., Van Merrienboer, J. J. G., \& Adam, J. (1994). Measurement of cognitive load in instructional research. Perceptual and motor skills, 79, 419-430. doi:10.2466/pms.1994.79.1.419

Papanikolaou, K., \& Mavromoustakos, S. (2006). Critical Success Factors for the Development of Mobile Learning Applications.

Park, Babette \& Moreno, Roxana \& Seufert, Tina \& Brünken, Roland. (2011). Does cognitive load moderate the seductive details effect? A multimedia study. Computers in Human Behavior. 27. 5-10. 10.1016/j.chb.2010.05.006.

Park, E., Han, J., Kim, K. J., Cho, Y., \& del Pobil, A. P. (2018). Effects of screen size in mobile learning over time.

Parsazadeh, N., Ali, R., \& Rezaei, M. (2018). A framework for cooperative and interactive mobile learning to improve online information evaluation skills. Computers \& Education, 120, 75-89. doi:https://doi.org/10.1016/j.compedu.2018.01.010

Raptis, D., Tselios, N., Kjeldskov, J., \& Skov, M. (2013). Does size matter? Investigating the impact of mobile phone screen size on users' perceived usability, effectiveness and efficiency.

Sanchez, C. A., \& Naylor, J. S. (2018). Disfluent presentations lead to the creation of more false memories. PLOS ONE, 13(1), e0191735. doi:10.1371/journal.pone.0191735

Shadiev, R., Hwang, W.-Y., Huang, Y.-M., \& Liu, T.-Y. (2015). The impact of supported and annotated mobile learning on achievement and cognitive load. Journal of Educational Technology \& Society, 18(4), 53-69.

Sluis, F., van den Broek, E. L., Drunen, A., \& Beerends, J. (2018). Mobile Screen Size Limits Multimodal Synergy.

So, S. (2016). Mobile instant messaging support for teaching and learning in higher education. The Internet and Higher Education, 31, 32-42. doi:https://doi.org/10.1016/j.iheduc.2016.06.001

Sweller, J. (1988). Cognitive Load During Problem Solving: Effects on Learning. Cognitive Science, 12(2), $257-$ 285. doi:10.1207/s15516709 $\operatorname{cog} 1202 \_4$

Sweller, J. (1994). Cognitive load theory, learning difficulty, and instructional design. Learning and Instruction,
4(4),

295-312.

https://doi.org/10.1146/annurev.anthro.33.070203.14 4008

Terras, Melody \& Ramsay, Judith. (2012). Terras, M.M \& Ramsay, J. (2012). Educational Applications of Web 2: A Psychological Perspective. Cyberpsychology and Computer Psychology Conference 2012 . CyComP 2012, Bolton, UK, July 16-17.

Triyason, T., \& Krathu, W. (2017). The impact of screen size toward QoE of cloud-based virtual desktop. Procedia Computer Science, 111, 203-208. doi:10.1016/j.procs.2017.06.054

Van Gerven, P. W. M., Paas, F., Van Merriënboer, J. J. G., \& Schmidt, H. G. (2004). Memory load and the cognitive pupillary response in aging. Psychophysiology, 41(2), 167-174. doi:10.1111/j.1469-8986.2003.00148.x

Wang, S., \& Higgins, M. (2005). Limitations of mobile phone learning (Vol. 2)

Wang, Y., Zhao, Z., Wang, D., Feng, G., \& Luo, B. (2013). How screen size influences Chinese readability.

Wenhao David, H., \& Jeanette, A. (2014). Design and Evaluation of Mobile Learning from the Perspective of Cognitive Load Management Handbook of Research on Education and Technology in a Changing Society (pp. 291-306). Hershey, PA, USA: IGI Global. 